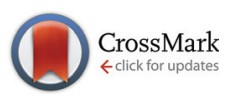

Cite this: DOI: 10.1039/c5ob00565e

\section{Ring size in cyclic endomorphin-2 analogs modulates receptor binding affinity and selectivity $\dagger$}

\author{
Justyna Piekielna, ${ }^{a}$ Alicja Kluczyk, ${ }^{b}$ Luca Gentilucci, ${ }^{c}$ Maria Camilla Cerlesi, ${ }^{d}$ \\ Girolamo Calo', ${ }^{d}$ Csaba Tomböly, ${ }^{e}$ Krzysztof Łapiński, ${ }^{f}$ Tomasz Janecki ${ }^{\mathrm{g}}$ and \\ Anna Janecka*a
}

Received 20th March 2015, Accepted 24th April 2015 DOI: 10.1039/c5ob00565e www.rsc.org/obc

\begin{abstract}
The study reports the solid-phase synthesis and biological evaluation of a series of new side chain-toside chain cyclized opioid peptide analogs of the general structure Tyr-[D-Xaa-Phe-Phe-Asp]NH $\mathrm{N}_{2}$, where $\mathrm{Xaa}=$ Lys (1), Orn (2), Dab (3), or Dap (4) (Dab = 2,4-diaminobutyric acid, Dap = 2,3-diaminopropionic acid), containing 17- to 14-membered rings. The influence of the ring size on binding to the MOP, DOP and KOP opioid receptors was studied. In general, the reduction of the size of the macrocyclic ring increased the selectivity for the MOP receptor. The cyclopeptide incorporating Xaa = Lys displayed subnanomolar MOP affinity but modest selectivity over the KOP receptor, while the analog with the Orn residue showed increased affinity and selectivity for MOP. The analog with Dab was a weak MOP agonist and did not bind to the other two opioid receptors. Finally, the peptide with Xaa = Dap was completely MOP receptor-selective with subnanomolar affinity. Interestingly, the deletion of one Phe residue from 1 led to the 14-membered Tyr-C[D-Lys-Phe-Asp] $\mathrm{NH}_{2}$ (5), a potent and selective MOP receptor ligand. The in vitro potencies of the new analogs were determined in a calcium mobilization assay performed in Chinese Hamster Ovary $(\mathrm{CHO})$ cells expressing human recombinant opioid receptors and chimeric $\mathrm{G}$ proteins. A good correlation between binding and the functional test results was observed. The influence of the ring size, solid support and the $\mathrm{N}$-terminal protecting group on the formation of cyclodimers was studied.
\end{abstract}

\section{Introduction}

The study of naturally occurring peptides provides a rational approach for the design of new drugs. A major goal in opioid peptide research is the development of novel analgesics which could replace morphine with its well-known side effects. ${ }^{1}$ Two endogenous tetrapeptide ligands of the MOP receptor, endomorphin-1 (EM-1, Tyr-Pro-Trp-Phe- $\mathrm{NH}_{2}$ ) and endomorphin-2 (EM-2, Tyr-Pro-Phe-Phe- $\mathrm{NH}_{2}$ ), ${ }^{2}$ display high antinociceptive

\footnotetext{
${ }^{a}$ Department of Biomolecular Chemistry, Faculty of Medicine, Medical University of Lodz, Lodz, Poland. E-mail: anna.janecka@umed.lodz.pl

${ }^{b}$ Faculty of Chemistry, University of Wroclaw, Wroclaw, Poland

'Department of Chemistry 'G. Ciamician', University of Bologna, via Selmi 2, 40126 Bologna, Italy

${ }^{d}$ Department of Medical Science, Section of Pharmacology, and National Institute of Neuroscience, University of Ferrara, 44121 Ferrara, Italy

${ }^{e}$ Institute of Biochemistry, Biological Research Centre of Hungarian Academy of Sciences, Szeged, Hungary

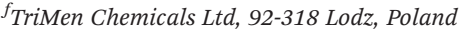

${ }^{g}$ Institute of Organic Chemistry, Lodz University of Technology, 90-924 Lodz, Poland $\dagger$ Electronic supplementary information (ESI) available. See DOI: 10.1039/ c5ob00565e
}

activity in several animal models of acute, inflammatory and neuropathic pain and are devoid of some serious side effects of morphine. ${ }^{3,4}$ However, native opioid peptides have several limitations, such as poor metabolic stability and inability to cross the blood-brain barrier (BBB), which distinguish them as therapeutic agents. ${ }^{5,6}$

To address these shortcomings of EMs and explore their structure-activity relationships, a variety of chemical modifications have been investigated. ${ }^{7-9}$ One such modification is cyclization, which is an efficient method to increase resistance to peptidases and can often be achieved without loss of activity. ${ }^{10}$ EMs are difficult to cyclize due to their short sequence and the lack of reactive side chain groups. Therefore, to obtain cyclic analogs of EMs various approaches have been used, such as elongation of their sequence or introduction of amino acid residues with functionalized side chains. Cardillo et al. synthesized a library of cyclic analogs of EM-1, containing a $\mathrm{Gly}^{5}$ bridge between $\mathrm{Tyr}^{1}$ and $\mathrm{Phe}^{4}$ and therefore deprived of the positively charged Tyr $N$-terminal amino group ${ }^{11}$ From this library, the cyclopeptide c[Tyr-D-Pro-D-TrpPhe-Gly] produced significant antinociception in a visceral pain model. ${ }^{12}$ 
Mollica et al. replaced $\mathrm{Pro}^{2}$ in the sequence of EM-2 by cis4-aminoproline (cAmp), introducing an additional amino group available for a side chain-to-tail cyclization reaction. The obtained 11-membered cyclopeptide Tyr-c[cAmp-Phe-Phe] was highly conformationally restricted, which drastically affected its binding to the MOP receptor. ${ }^{13}$ Assigning a different stereochemistry to both Phe residues present in the ring led to the modulation of the opioid receptor affinity. ${ }^{14}$

In our effort to obtain cyclic EM-2 analogs, we adopted a side chain-to-side chain approach based on the incorporation of two bivalent amino acids in positions 2 and 5 of a pentapeptide backbone. ${ }^{15,16}$ Some of the thus obtained cyclic analogs showed significantly increased activity and bioavailability. Recently, we used liquid chromatography combined with online mass spectrometry (LC-MS) and tandem mass spectrometry (LC-MS/MS) to study the cyclization reaction of EM-2 analogs. ${ }^{17}$ Cyclization of the pentapeptides Tyr/Dmt-D-Lys-PhePhe-Asp- $\mathrm{NH}_{2}$ (where Dmt $=2^{\prime}, 6^{\prime}$-dimethyltyrosine) through an amide bond on the MBHA Rink Amide resin resulted in the formation of cyclic monomers and cyclic but not linear dimers. The comparison of the cyclic monomer/dimer ratios for analogs with Tyr versus Dmt in position 1 revealed that the presence of the exocyclic Dmt favored the formation of the cyclic monomer, most likely due to the increased steric bulk of this amino acid side chain, as compared with Tyr.

Here, continuing our structure-activity relationship studies of EM-2 cyclic analogs, we assessed the influence of the ring size on the affinity, selectivity and potency of analogs at the three opioid receptors. Additionally, the impact of the ring size and the type of a solid-phase support used for the synthesis on the amount of side-product formation was studied.

\section{Materials and methods}

\section{General methods}

All reagents, unless otherwise stated, were purchased from Sigma Aldrich (Poznan, Poland). Protected amino acids were purchased from Bachem AG (Bubendorf, Switzerland) or obtained from TriMen Chemicals Ltd (Lodz, Poland). Opioid radioligands, $\left[{ }^{3} \mathrm{H}\right]$ DAMGO, $\left[{ }^{3} \mathrm{H}\right]\left[\right.$ Ile $\left.{ }^{5,6}\right]$ deltorphin-2 and $\left[{ }^{3} \mathrm{H}\right]$ norbinaltorphimine (nor-BNI) were synthesized in the Biological Research Centre of Hungarian Academy of Sciences (Szeged, Hungary). Analytical and semi-preparative RP-HPLC was performed using a Waters Breeze instrument (Milford, MA, USA) with a dual absorbance detector (Waters 2487) on a Vydac $\mathrm{C}_{18}$ column $(5 \mu \mathrm{m}, 4.6 \times 250 \mathrm{~mm})$ and a Vydac $\mathrm{C}_{18}$ column $(10 \mu \mathrm{m}$, $22 \times 250 \mathrm{~mm}$ ), respectively. High resolution mass spectra were recorded using a Bruker micrOTOF-Q mass spectrometer (Bruker Daltonics, Bremen, Germany) with electrospray ionization (ESI-MS). The instrument was operated in the positive-ion mode and calibrated with the Tunemix ${ }^{\mathrm{TM}}$ mixture (Agilent Technologies, Palo Alto, CA, USA). For LC-MS analysis, an Agilent 1200 chromatograph (Agilent Technologies, Palo Alto, CA, USA) equipped with an Aeris Peptide $\mathrm{XB}^{-\mathrm{C}_{18}}$ column $(3.6 \mu \mathrm{m}, 2.1 \times 50 \mathrm{~mm})$ (Phenomenex, Torrence, CA, USA) was used. For LC-MS and LC-MS/MS studies a linear gradient of 10-50\% B in A over 25 min was applied (A: $0.1 \%$ formic acid in water, $\mathrm{B}: 0.1 \%$ formic acid in acetonitrile, flow rate $0.1 \mathrm{~mL}$ $\left.\min ^{-1}\right) .{ }^{1} \mathrm{H}-\mathrm{NMR}$ spectra were recorded in DMSO- $d_{6}$ on a Bruker Avance II+ $700 \mathrm{MHz}$ spectrometer and the chemical shifts were reported as $\delta$ values relative to residual DMSO $\left(\delta_{\mathrm{H}}=\right.$ $2.50 \mathrm{ppm}$ ) as an internal standard. $J$ values are given in $\mathrm{Hz}$.

\section{Synthesis of peptides}

Peptides were synthesized on MBHA Rink-Amide peptide resin (100-200 mesh, $0.8 \mathrm{mM} \mathrm{g}^{-1}$, Novabiochem) using Fmoc-protected amino acids. ${ }^{18}$ The hydroxyl group of Tyr was protected by a $t$-Bu group and the hyper-acid labile $\mathrm{Mtt} / \mathrm{O}-2 \mathrm{Ph} i \mathrm{Pr}$ groups were used for the selective D-Lys/D-Orn/D-Dab/D-Dap and Asp side chain protection, respectively. TBTU was used as a coupling agent. Fully assembled Fmoc-protected peptides were treated with 1\% TFA in DCM to remove side chain protecting groups (Mtt and $\mathrm{O}-2 \mathrm{Ph} i \mathrm{Pr}$ ), followed by the on-resin cyclization with TBTU. After the removal of a Fmoc group from Tyr, peptides were cleaved from the resin with a TFA/TIS/ $\mathrm{H}_{2} \mathrm{O}$ mixture $(95: 2.5: 2.5)$ for $3 \mathrm{~h}$ at room temperature.

Alternatively, MBHA amide peptide resin (100-200 mesh, $0.8 \mathrm{mM} \mathrm{g}^{-1}$, Novabiochem) was used with Boc-protected amino acids. ${ }^{15}$ The hydroxyl group of Tyr was protected by 2-Br-Z, while Fmoc was used for the side chain amino group protection of D-Lys and D-Orn and the $\beta$-carboxy group of Asp was blocked by OFm. 50\% TFA in DCM was used for the deprotection of Boc-groups and TBTU was employed for coupling. Fully assembled Boc-protected peptides were treated with $20 \%$ piperidine in DMF to remove base-labile groups (Fmoc and OFm), followed by cyclization with TBTU. Simultaneous deprotection of Tyr and cleavage of peptides from the resin were accomplished by treatment with $\mathrm{HBr}(33 \%$ in $\mathrm{AcOH}) / \mathrm{TFA} /$ thioanisole $(0.4: 10: 0.5)(3 \times 30 \mathrm{~min})$ at room temperature.

The crude peptide salts were purified by RP-HPLC using a linear gradient of $0-100 \% \mathrm{~B}$ over $40 \mathrm{~min}$ at the flow rate of $15 \mathrm{~mL} \mathrm{~min}^{-1}$, with UV detection at $214 \mathrm{~nm}$ (injection volume $0.5 \mathrm{~mL}$ ). Solvents: A: $0.1 \%$ TFA in water and B: $0.1 \%$ TFA in acetonitrile/water $(80: 20, \mathrm{v} / \mathrm{v})$. The purity of the final peptides was verified by analytical RP-HPLC in the same solvent system over $25 \mathrm{~min}$ with the flow rate of $1 \mathrm{~mL} \mathrm{~min}^{-1}$. The synthesized compounds were characterized by ESI-MS (Table 1) and ${ }^{1} \mathrm{H}-\mathrm{NMR}$.

Tyr-c[D-Lys-Phe-Phe-Asp] $\mathrm{NH}_{2} \quad 1 \quad{ }^{1} \mathrm{H}-\mathrm{NMR}$ was described previously. ${ }^{16}$

Tyr-c[D-Orn-Phe-Phe-Asp] $\mathrm{NH}_{2} 2$ (DMSO- $\left.d_{6}\right) \delta: 1.03(\mathrm{~m}, 1 \mathrm{H})$, $1.20(\mathrm{~m}, 1 \mathrm{H}), 1.35(\mathrm{~m}, 1 \mathrm{H}), 1.46(\mathrm{~m}, 1 \mathrm{H}), 2.37-2.48(\mathrm{~m}, 2 \mathrm{H})$, 2.79-2.85 (m, 3H), 2.87-2.97 (m, 2H), 3.00-3.06 (m, 2H), 3.08 $(\mathrm{dd}, J=14.0, J=7.0,1 \mathrm{H}), 4.02(\mathrm{~m}, 1 \mathrm{H}), 4.12(\mathrm{q}, J=7.7,1 \mathrm{H})$, $4.26(\mathrm{~m}, 1 \mathrm{H}), 4.42(\mathrm{q}, J=7.0,1 \mathrm{H}), 4.57(\mathrm{~m}, 1 \mathrm{H}), 6.73(\mathrm{~d}, J=8.4$, $2 \mathrm{H}), 7.02-7.27(\mathrm{~m}, 12 \mathrm{H}), 7.86(\mathrm{~d}, J=7.0,1 \mathrm{H}), 7.88(\mathrm{t}, J=6.3$, $1 \mathrm{H}), 7.97$ (d, $J=6.31 \mathrm{H}), 8.05(\mathrm{~d}, J=9.1,1 \mathrm{H}), 8.13(\mathrm{bs}, 2 \mathrm{H}), 8.44$ (d, $J=7.7,1 \mathrm{H}), 9.37$ (s, 1H).

Tyr-c[D-Dab-Phe-Phe-Asp] $\mathrm{NH}_{2} 3{ }^{1} \mathrm{H}-\mathrm{NMR}\left(\mathrm{DMSO}_{6}\right) \delta: 1.52$ $(\mathrm{m}, 1 \mathrm{H}), 1.79(\mathrm{~m}, 1 \mathrm{H}), 2.29(\mathrm{~m}, 1 \mathrm{H}), 2.68-2.73(\mathrm{~m}, 2 \mathrm{H})$, 2.81-2.86 (m, 2H), 2.96-3.08 (m, 2H), 3.18 (dd, $J=14.0, J=6.3$, 
Table 1 Analytical data of novel cyclic analogs

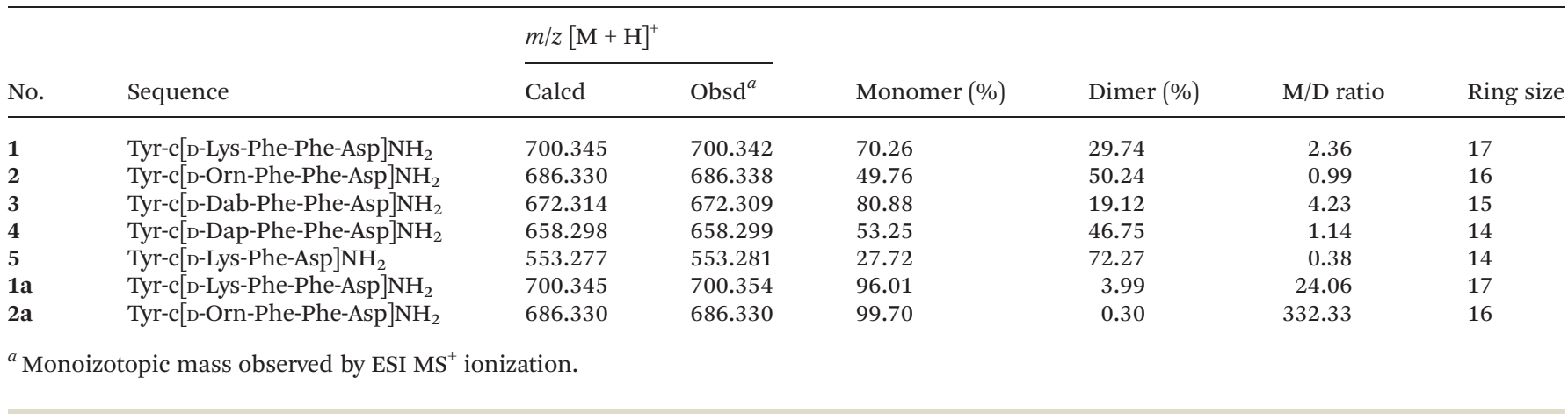

$1 \mathrm{H}), 3.93(\mathrm{~m}, 1 \mathrm{H}), 4.17(\mathrm{~m}, 1 \mathrm{H}), 4.21(\mathrm{q}, J=7.7,1 \mathrm{H}), 4.37(\mathrm{~m}$, $1 \mathrm{H}), 4.46(\mathrm{~m}, 1 \mathrm{H}), 4.55-4.63(\mathrm{~m}, 2 \mathrm{H}), 6.72(\mathrm{~d}, J=8.4,2 \mathrm{H})$, 6.99-7.29 (m, 12H), $7.48(\mathrm{t}, J=6.3,1 \mathrm{H}), 8.01(\mathrm{~d}, J=7.0,1 \mathrm{H})$, $8.12(\mathrm{~d}, J=7.7,1 \mathrm{H}), 8.36$ (bs, $2 \mathrm{H}), 8.47$ (d, $J=7.7,1 \mathrm{H}), 9.36$ (s, $1 \mathrm{H})$.

Tyr-c[D-Dap-Phe-Phe-Asp] $\mathrm{NH}_{2} 4{ }^{1} \mathrm{H}-\mathrm{NMR}\left(\mathrm{DMSO}_{6}\right) \delta: 2.29$ $(\mathrm{dd}, J=8.4, J=4.2,1 \mathrm{H}), 2.65-2.79(\mathrm{~m}, 4 \mathrm{H}), 2.84(\mathrm{dd}, J=9.1, J=$ 4.9, 1H), 2.93-3.06 (m, 2H), $3.27(\mathrm{~m}, 1 \mathrm{H}), 3.75(\mathrm{~m}, 1 \mathrm{H}), 3.97$ $(\mathrm{m}, 1 \mathrm{H}), 4.03-4.07(\mathrm{~m}, 2 \mathrm{H}), 4.40(\mathrm{~m}, 1 \mathrm{H}), 4.47(\mathrm{q}, J=6.3,1 \mathrm{H})$, $6.74(\mathrm{~d}, J=8.4,2 \mathrm{H}), 7.04-7.06(\mathrm{~m}, 6 \mathrm{H}), 7.15-7.28(\mathrm{~m}, 7 \mathrm{H}), 7.61$ $(\mathrm{d}, J=8.4,1 \mathrm{H}), 7.64(\mathrm{dd}, J=7.0, J=4.9,1 \mathrm{H}), 8.16(\mathrm{bs}, 2 \mathrm{H}), 8.44$ $(\mathrm{d}, J=8.4,1 \mathrm{H}), 8.72(\mathrm{~d}, J=7.0,1 \mathrm{H}), 9.39(\mathrm{~s}, 1 \mathrm{H})$.

Tyr-c[D-Lys-Phe-Asp] $\mathrm{NH}_{2} 5{ }^{1} \mathrm{H}-\mathrm{NMR}\left(\mathrm{DMSO}_{6}\right) \delta: 0.89-0.98$ (m, 2H), 1.12-1.24 (m, 2H), $1.34(\mathrm{~m}, 1 \mathrm{H}), 1.45(\mathrm{~m}, 1 \mathrm{H}), 2.30$ $(\mathrm{dd}, J=14.7, J=11.9,1 \mathrm{H}), 2.44(\mathrm{dd}, J=14.0, J=2.8,1 \mathrm{H}), 2.68$ $(\mathrm{dd}, J=14.0, J=7.0,1 \mathrm{H}), 2.76(\mathrm{~m}, 1 \mathrm{H}), 2.82-2.93(\mathrm{~m}, 2 \mathrm{H}), 3.06$ (dd, $J=14.0, J=7.7,1 \mathrm{H}), 3.43(\mathrm{~m}, 1 \mathrm{H}), 3.94(\mathrm{~m}, 1 \mathrm{H}), 4.07$ (m, $1 \mathrm{H}), 4.59-4.55(\mathrm{~m}, 2 \mathrm{H}), 6.72(\mathrm{~d}, J=9.0,2 \mathrm{H}), 7.01(\mathrm{~d}, J=9.0$, $2 \mathrm{H}), 7.15-7.17(\mathrm{~m}, 3 \mathrm{H}), 7.22-7.24(\mathrm{~m}, 2 \mathrm{H}), 7.47(\mathrm{~d}, J=8.4, J=$ $35,1 \mathrm{H}), 7.78(\mathrm{t}, J=7.0,1 \mathrm{H}), 7.79(\mathrm{t}, J=8.4,1 \mathrm{H}), 8.11(\mathrm{bs}, 2 \mathrm{H})$, $8.17(\mathrm{~d}, J=7.0,1 \mathrm{H}), 9.36(\mathrm{~s}, 1 \mathrm{H})$.

\section{Determination of monomer/dimer ratios}

The crude products were subjected to LC-MS analysis to determine the monomer/dimer (M/D) ratio. LC-MS chromatograms were analysed using Bruker Compass Data Analysis 4.0 software by extracting the traces of chromatograms for expected $\mathrm{m} / \mathrm{z}$ values for protonated product ions (XIC). The peaks were identified by analysis of mass spectra representing the selected LC-MS signals and confirmed by additional MS/MS and LC-MS/MS experiments. The obtained chromatograms were integrated and the peak areas were compared to obtain the $\mathrm{M} / \mathrm{D}$ ratio.

\section{Opioid receptor binding assays}

The receptor binding assays were performed according to the modified method described by Misicka et al. ${ }^{19}$ Binding affinities for all three opioid receptors, MOP, DOP and KOP, were determined by displacing, respectively, $\left[{ }^{3} \mathrm{H}\right]$ DAMGO and $\left[{ }^{3} \mathrm{H}\right]\left[\right.$ Ile $\left.^{5,6}\right]$ deltorphin-2 from Wistar rat brain membrane binding sites and $\left[{ }^{3} \mathrm{H}\right]$ nor-BNI from guinea pig brain mem- branes. Briefly, crude membrane preparations were incubated at $25{ }^{\circ} \mathrm{C}$ for $120 \mathrm{~min}$ with appropriate concentrations of a tested peptide in the presence of $0.5 \mathrm{nM}$ radioligand in a total volume of $0.5 \mathrm{~mL}$ of $50 \mathrm{mM}$ Tris $/ \mathrm{HCl}(\mathrm{pH} 7.4)$ containing bovine serum albumin (BSA) $\left(1 \mathrm{mg} \mathrm{mL}^{-1}\right)$, bacitracin $(50 \mu \mathrm{g}$ $\left.\mathrm{mL}^{-1}\right)$, bestatin $(30 \mu \mathrm{M})$ and captopril $(10 \mu \mathrm{M})$. Non-specific binding was determined in the presence of $1 \mu \mathrm{M}$ naloxone. Incubations were terminated by rapid filtration through the GF/B Whatman (Brentford, UK) glass fiber strips (pre-soaked for $2 \mathrm{~h}$ in $0.5 \%(\mathrm{v} / \mathrm{v})$ polyethylamine) using Millipore Sampling Manifold (Billerica, USA). The filters were washed three times with $4 \mathrm{~mL}$ of ice-cold Tris buffer solution. The bound radioactivity was measured in a Packard Tri-Carb 2100 TR liquid scintillation counter (Ramsey, MN, USA) after overnight extraction of the filters in $4 \mathrm{~mL}$ of a Perkin Elmer Ultima Gold scintillation fluid (Wellesley, MA, USA). Three independent experiments for each assay were carried out in duplicate. The data were analyzed by a nonlinear least squares regression analysis computer program, GraphPad PRISM 5.0 (GraphPad Software Inc., San Diego, U.S.A.).

\section{Calcium mobilization assay}

Chinese Hamster Ovary (CHO) cells stably co-expressing human recombinant MOP or KOP and the C-terminally modified $\mathrm{G} \alpha_{\mathrm{qi} 5}$ and $\mathrm{CHO}$ cells co-expressing the human recombinant DOP receptor and the $\mathrm{G} \alpha_{\mathrm{qG} 66 \mathrm{Di} 5}$ chimeric protein were generated as previously described..$^{20-22}$ Cells were cultured in Dulbecco's modified Eagle's medium (DMEM)/HAMS F12 (1:1) supplemented with $10 \%$ fetal calf serum, penicillin (100 IU mL $\mathrm{mL}^{-1}$ ), streptomycin (100 $\mathrm{mg} \mathrm{mL}^{-1}$ ), geneticin (G418; $\left.200 \mu \mathrm{g} \mathrm{mL} \mathrm{m}^{-1}\right)$ and hygromycin $\mathrm{B}\left(100 \mu \mathrm{g} \mathrm{mL} \mathrm{m}^{-1}\right)$ and kept at $37{ }^{\circ} \mathrm{C}$ in a $5 \% \mathrm{CO}_{2} /$ humidified air. When confluence was reached (3-4 days), cells were sub-cultured using trypsin/EDTA and used for the assay.

Cells were seeded at a density of 50000 cells per well into 96-well black, clear-bottom plates. After $24 \mathrm{~h}$ incubation, the cells were loaded with Hank's Balanced Salt Solution (HBSS) supplemented with $2.5 \mathrm{mM}$ probenecid, $3 \mu \mathrm{M}$ of the calcium sensitive fluorescent dye Fluo- $4 \mathrm{AM}, 0.01 \%$ pluronic acid and $20 \mathrm{mM}$ HEPES ( $\mathrm{pH} 7.4$ ) for $30 \mathrm{~min}$ at $37^{\circ} \mathrm{C}$. The loading solution was aspirated and cells were washed with $100 \mu \mathrm{L}$ per well 
of HBSS, HEPES (20 mM, pH 7.4), $2.5 \mathrm{mM}$ probenecid and $500 \mu \mathrm{M}$ Brilliant Black. Then $100 \mu \mathrm{L}$ per well of the same buffer was added. Peptides were dissolved in 1\% DMSO in bidistilled water at a final concentration of $1 \mathrm{mM}$. The successive dilutions were made in the HBSS/HEPES (20 mM) buffer (containing $0.005 \%$ BSA fraction $\mathrm{V}$ ).

After placing both plates (cell culture and compound plate) into the FlexStation II, the on-line additions were carried out in a volume of $50 \mu \mathrm{L}$ per well and fluorescence changes were measured at $37^{\circ} \mathrm{C}$.

Agonist potencies are given as $\mathrm{pEC}_{50}$ that is the negative logarithm of the molar concentration of an agonist that produces $50 \%$ of the maximal possible effect. Concentrationresponse curves were fitted with the four parameter logistic nonlinear regression model

$$
\text { Effect }=\text { baseline }+\frac{E_{\max }-\text { baseline }}{1+10^{\left(\log \mathrm{EC}_{50}-X\right) n}}
$$

where $X$ is the agonist concentration and $n$ is the Hill coefficient. Ligand efficacy was expressed as intrinsic activity $(\alpha)$ calculated as the ratio of $E_{\max }$ of the ligand to $E_{\max }$ of the standard agonist. At least four separate experiments were performed in duplicate. Curve fittings were performed using GraphPad PRISM 5.0 (GraphPad Software Inc., San Diego, U.S.A.). Data have been statistically analyzed with one way ANOVA followed by the Dunnett's test for multiple comparisons; $p$ values less than 0.05 were considered to be significant.

\section{Molecular dynamics simulations}

Molecular dynamics (MD) simulations were performed using the AMBER force field in a $30 \times 30 \times 30 \AA$ box of standard TIP3P water for $10 \mathrm{~ns}$ at $298 \mathrm{~K}^{23-25}$ Periodic boundary conditions were applied at constant temperature and pressure (Berendsen scheme, a bath relaxation constant of 0.2 ). ${ }^{26} \mathrm{~A}$ dielectric constant of 1 was used and the cut-off distance for the non-bonded interactions was $12 \AA$. All water molecules with atoms that come closer than $2.3 \AA$ to a solute atom were eliminated. For 1-4 scale factors, van der Waals and electrostatic interactions were scaled in AMBER to half their nominal value. The integration time step was set to 0.1 fs. The system coordinates were collected every picosecond.

\section{Results and discussion}

\section{Influence of the resin type and $\mathrm{N}$-terminal protection on dimer formation}

All peptides were synthesized by the conventional solid-phase procedure on the MBHA Rink Amide resin, using techniques for Fmoc-protected amino acids with the hyper-acid labile Mtt/ $\mathrm{O}-2 \mathrm{Ph} i \mathrm{Pr}$ groups for the selective amine/carboxyl side chain protection of the basic amino acids and Asp, respectively, that, after deprotection, would enable on-resin cyclization. ${ }^{27,28}$ For comparison, analogs $\mathbf{1}$ and $\mathbf{2}$ were re-synthesized on the MBHA Amide resin using the Boc strategy with Fmoc and OFm groups for the selective amine/carboxyl side chain protection of D-Lys/D-Orn and Asp, respectively.

High resolution mass spectrometry (LS-MS and MS/MS) experiments confirmed the identity of all the synthesized peptides. RP-HPLC analyses of the final purified products indicated a purity of $97 \%$ or greater (Table 1 ).

The LC-MS chromatograms were examined to obtain the extracted ion chromatograms (XIC) for calculated $\mathrm{m} / \mathrm{z}$ values of protonated peptides 1-5. In the case of the Fmoc-based procedure (peptides 1-5) there were two peaks corresponding to the expected $\mathrm{m} / \mathrm{z}$ values in the respective chromatograms. The mass spectra corresponding to these peaks revealed different distributions of isotopic peaks, characteristic of the single charge $(+1)$ ions (for the faster eluting compounds) and double charge $(+2)$ ions (for the slower eluting compounds). Therefore, the calculated molecular masses indicated the monomeric and dimeric compositions of these forms of peptides. The energy required for fragmentation in collision induced dissociation experiments (CID MS/MS), as well as the analysis of MS/MS spectra confirmed the dimeric character of the second cyclic product. The LC-MS and MS/MS procedures for the identification of the dimeric form of peptides were discussed in detail previously. ${ }^{17}$

The $\mathrm{M} / \mathrm{D}$ ratios in the crude mixtures of peptides 1-4 of a general structure Tyr-c[D-Xaa-Phe-Phe-Asp] $\mathrm{NH}_{2}$, where Xaa was Lys, Orn, Dab or Dap, synthesized by the Fmoc-strategy, varied from 0.99 to 4.23 and depended on the size of the ring (Table 1). However, a straightforward relationship between the dimer amount and the ring size was not observed. The peptide incorporating the Dab residue (15-membered ring) contained about $81 \%$ of the desired monomer in the crude mixture, the analog with Lys (17-membered ring) about 70\%, while the cyclic analogs with Orn and Dap residues (16 and 14-membered rings, respectively) were formed in only about $50 \%$ yield. It seems that an uneven number of atoms forming the ring favored monomer formation.

Another interesting observation was that in the case of analogs 4 and 5, both containing 14-membered rings, different amounts of monomers were formed (53.25 and $27.72 \%$, respectively). The difference between these two analogs is that 5 is a tetrapeptide incorporating the Lys residue with its long side chain, while 4 is a pentapeptide incorporating a short side chain Dap. It seems that the amino group at the end of a flexible 4-carbon side chain of Lys can easily reach the $\beta$-carboxyl of Asp of a neighboring peptide forming a dimer. On the other hand, a short, more rigid side chain of Dap is less likely to form intramolecular bonds and favors monomer formation.

Analogs 1 and 2 were then re-synthesized on the MBHA Amide resin using the Boc strategy (peptides 1a and 2a). In this case, the monomeric forms dominated in LC-MS chromatograms. A thorough search revealed that the dimeric forms were also present but the intensities of XIC peaks were below the standard selection limit of the software and manual selection and integration of peaks was required to obtain the data for ratio calculations. Fig. 1 presents the exemplary LC-MS 


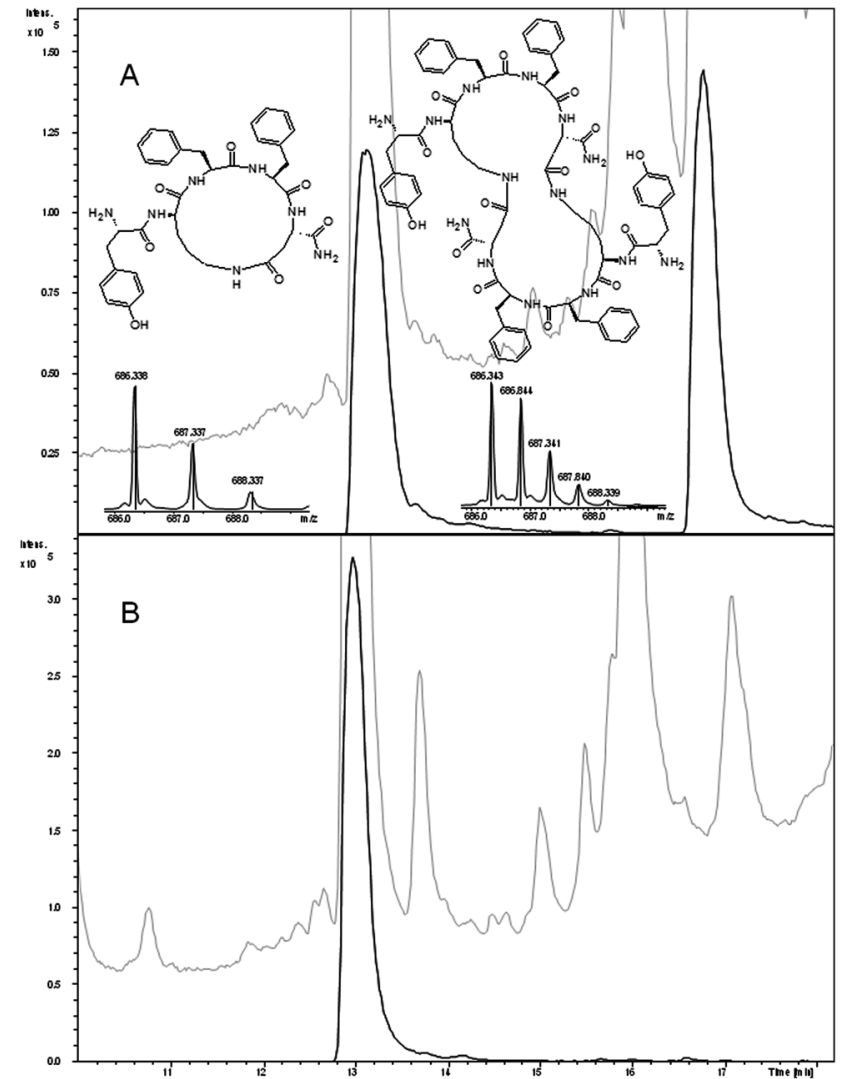

Fig. 1 LC-MS chromatograms recorded for crude products 2 (Fmoc synthesis, panel A) and $2 a$ (Boc synthesis, panel B). Insets in A present fragments of MS spectra recorded for peaks at retention times $13.3 \mathrm{~min}$ and $17.0 \mathrm{~min}$ and molecular structures of monomeric and dimeric forms of peptide 2. Gray line: total ion chromatograms, black line: extracted ion chromatograms (XIC) for $\mathrm{m} / \mathrm{z} 686.33$. The intensity scale of chromatograms was adjusted to the present XIC as full scale signals.

chromatograms of crude peptide 2 synthesized on the MBHA Rink Amide and MBHA Amide resins.

The difference between MBHA Rink Amide and MBHA Amide resins is that in the first one the active $\mathrm{NH}_{2}$ group is moved away from the resin by a long spacer, while in the second the $\mathrm{NH}_{2}$ group is situated much closer to the solid support. Therefore, it could be speculated that the steric hindrance caused by the proximity of the MBHA Amide resin surface prevents the formation of intramolecular bonds. For dimer formation, an antiparallel orientation of peptide chains is required, which supports the demand for a flexible linker.

Yet another aspect that should be taken into consideration when the amount of dimer formation is discussed is the presence of different protecting groups (Fmoc or Boc) on the exocyclic Tyr residue during cyclization. It could be speculated that these protecting groups may enforce different conformations of a peptide chain which either favor dimerization or make it almost impossible.

\section{Biological studies}

Opioid receptor binding studies. Opioid binding affinities of cyclic analogs 1-5 for the MOP, DOP and KOP receptors were determined by radioligand competition analysis using $\left[{ }^{3} \mathrm{H}\right]$ DAMGO, $\left[{ }^{3} \mathrm{H}\right]\left[\mathrm{Ile}^{5,6}\right]$ deltorphin-2 and $\left[{ }^{3} \mathrm{H}\right]$ nor-BNI, respectively. These data, calculated as $\mathrm{IC}_{50}$ values, are summarized in Table 2. Pentapeptides $\mathbf{1}$ and $\mathbf{2}$ exhibited subnanomolar affinity for MOP and nanomolar for KOP, while 3 and especially 4 were MOP selective. Analogs 2-4 did not bind to DOP while 1 showed a weak affinity for this receptor. Compound $\mathbf{5}$ is a cyclic tetrapeptide with only one Phe residue and cannot be considered an EM-2 analog. Nevertheless, this analog showed very high affinity for MOP and weak affinity for the other two opioid receptors. It seems that the binding pocket of the MOP receptor can accommodate a variety of ligands.

\section{Functional assay}

The pharmacological profiles of analogs 1-5 were characterized in vitro at all three opioid receptors in the calcium mobilization assay. ${ }^{22}$ The calculated agonist potencies $\left(\mathrm{pEC}_{50}\right)$ and efficacies $(\alpha)$ of the analogs are summarized in Table 3. EM-2, DPDPE, and dynorphin A were used as the reference agonists

Table 2 Opioid receptor binding data of the cyclic analogs ${ }^{a}$

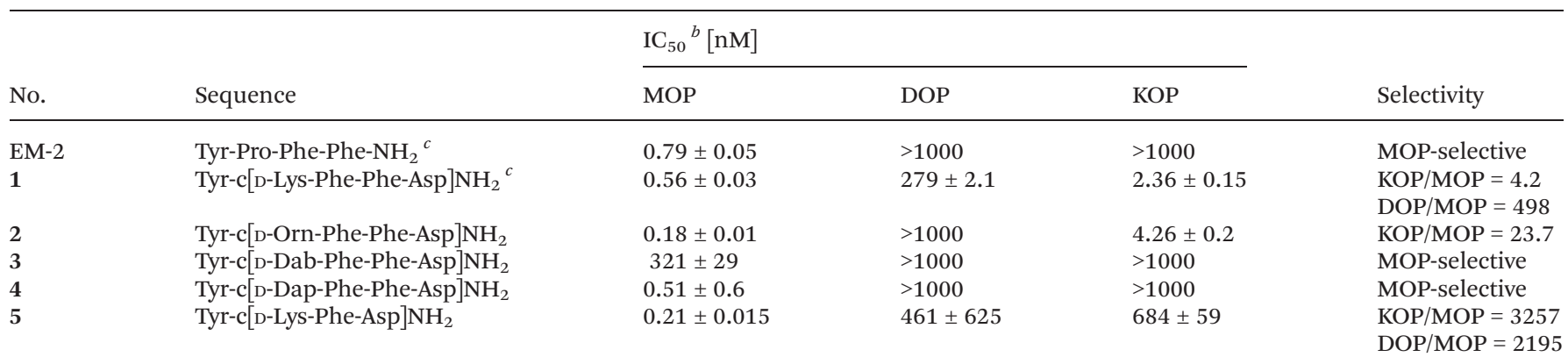

${ }^{a}$ All values are expressed as means \pm SEM for three independent experiments performed in duplicate. ${ }^{b}$ Binding affinity values were determined by competitive displacement of the selective radioligands, $\left[{ }^{3} \mathrm{H}\right] \mathrm{DAMGO},\left[{ }^{3} \mathrm{H}\right]\left[\mathrm{Ile}{ }^{5,6}\right]$ deltorphin-2 and $\left[{ }^{3} \mathrm{H}\right]$ nor-BNI for MOP, DOP and KOP respectively. All values are expressed as means \pm SEM for three independent experiments performed in duplicate. ${ }^{c}$ Data from ref. 15 . 
Table 3 Effects of reference agonists and EM-2 derivatives at human recombinant opioid receptors coupled with calcium signaling via chimeric G proteins $^{a}$

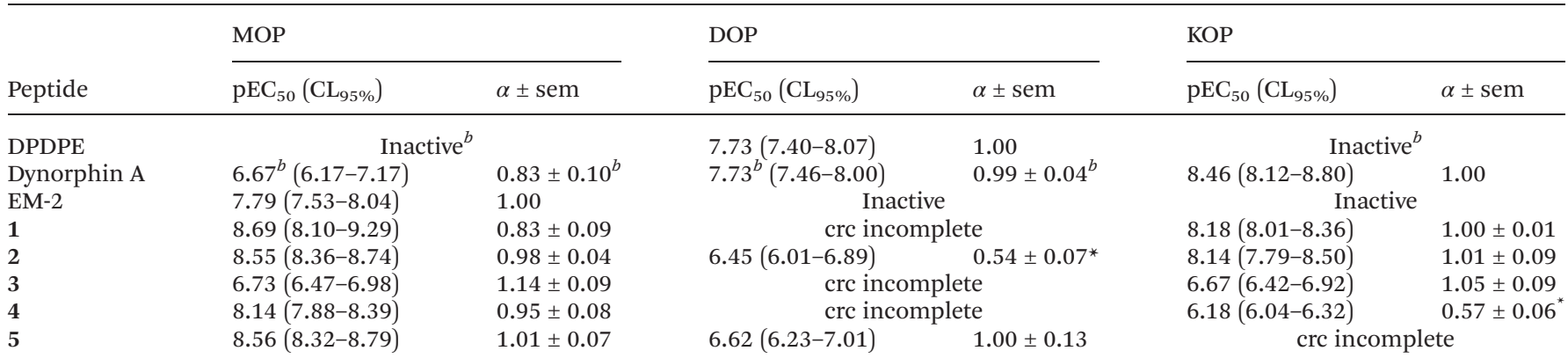

${ }^{a}$ Inactive means that the compound was inactive up to $1 \mu \mathrm{M}$. The crc incomplete means that maximal effects could not be determined due to the low potency of the compounds. DPDPE, dynorphin A and EM-2 were used as reference agonists for calculating the intrinsic activity at DOP, KOP and MOP receptor respectively. ${ }^{b}$ Data are from ref. $22 .{ }^{*} p<0.05$ was considered significant according to one way ANOVA followed by the Dunnett's test for multiple comparisons.
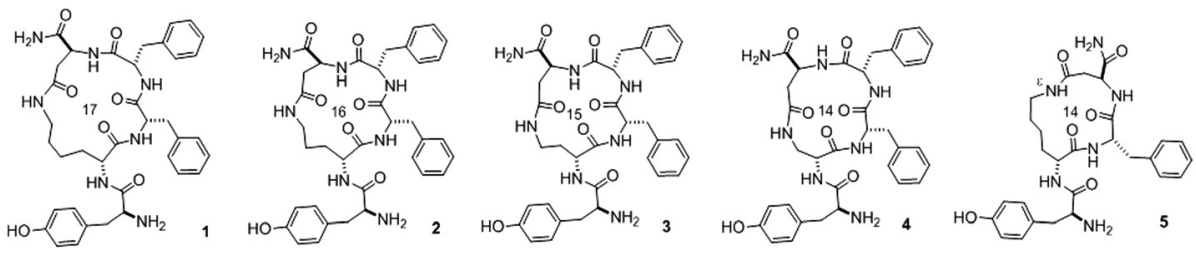

Tyr-c[D-Lys-Phe-Phe-AsplNH $H_{2}$ Tyr-c[D-Orn-Phe-Phe-Asp] $\mathrm{NH}_{2}$ Tyr-c[D-Dab-Phe-Phe-Asp] $\mathrm{NH}_{2}$

Tyr-c[D-Dap-Phe-Phe-Asp] $\mathrm{NH}_{2}$

Tyr-c[D-Lys-Phe-Asp]NH2

Fig. 2 Sketches of the structures of cyclopeptides 1-5 with the 17 to 14-membered rings.

for calculating the intrinsic activity at the MOP, DOP, and KOP receptor, respectively.

Results of this study demonstrated that peptides $\mathbf{1}$ and 2 behaved as mixed MOP/KOP receptor agonists with high potency. Peptide 3 showed a similar low potency for MOP and KOP receptors. Compounds $\mathbf{4}$ and $\mathbf{5}$ acted as selective and highly potent full MOP agonists.

\section{Correlation between ring size and receptor affinity/selectivity}

The comparison of the biological results for the cyclopeptides 1-5 reported in Table 1 highlighted an apparent correlation between selectivity for the MOP receptor and the ring size (Fig. 2). The largest cyclopeptide 1, Tyr-c[D-Lys-Phe-Phe-Asp]$\mathrm{NH}_{2}$, which includes the D-Lys connector and comprises 17 bonds in the ring, was an excellent MOP receptor ligand with an $\mathrm{IC}_{50}$ of $0.56 \mathrm{nM}$, but showed a moderate selectivity over the $\mathrm{KOP}$ receptor $(\mathrm{KOP} / \mathrm{MOP}=4.2)$. The introduction of $\mathrm{D}-\mathrm{Orn}$ in place of D-Lys in 2 reduced the ring size to 16 and increased the MOP receptor affinity $(0.18 \mathrm{nM})$ and selectivity over KOP $(\mathrm{KOP} / \mathrm{MOP}=23.7)$, while the 15 -membered cyclopeptide 3 containing D-Dab showed poor affinity to the MOP receptor $\left(\mathrm{IC}_{50}\right.$ in the $10^{-7} \mathrm{M}$ range) but some selectivity, since it did not bind to the other two receptors up to the $10^{-6} \mathrm{M}$ concentration. Finally, the 14-membered 4 showed a similar to 1 MOP affinity (0.51 nM) and was totally MOP receptor selective. Interestingly, also peptide 5, Tyr-c[D-Lys-Phe-Asp] $\mathrm{NH}_{2}$, deprived of one Phe residue, still maintained subnanomolar affinity for the MOP and high selectivity over DOP and KOP receptors, confirming the optimality of the 14 membered ring size.

Previous experiments revealed that the parent cyclopeptide 1 (Tyr-c[D-Lys-Phe-Phe-Asp] $\mathrm{NH}_{2}$ ) adopted in a biomimetic solvent system (8:2 DMSO- $\left.d_{6} / \mathrm{H}_{2} \mathrm{O}\right)$ a compact conformation, not characterized by the secondary structure elements (Fig. 3, 1 in solution). ${ }^{29}$ On the other hand, molecular docking analy-

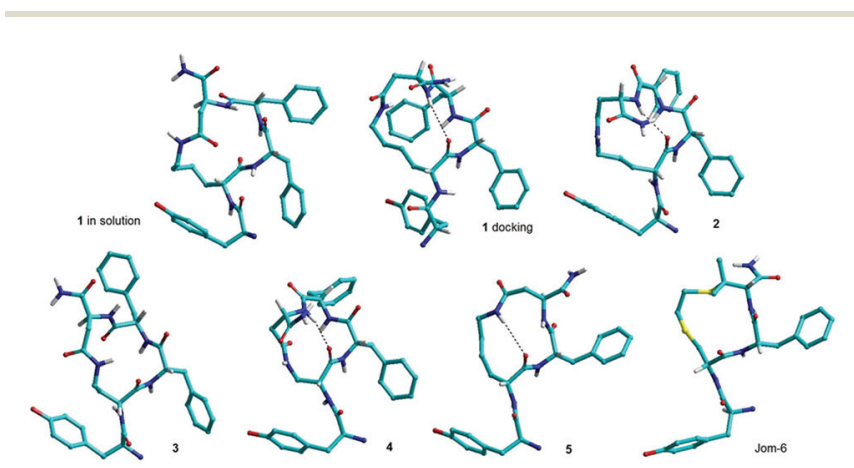

Fig. 3 In solution and bioactive (i.e. MOP receptor-docked) structures of 1; representative structures of 2-5 observed during a molecular dynamics simulation in a $30 \times 30 \times 30 \AA$ box of standard TIP3P water, accounting for the experimentally observed MOP receptor affinities and selectivities (Table 1); bioactive structure of Jom-6. For clarity, only amide $\mathrm{NH}$ and $\alpha$-protons are shown. 
$\operatorname{sis}^{29}$ performed on our model of the human MOP receptor, obtained by homology modelling ${ }^{30}$ subsequently validated using the crystallographic structure disclosed in 2012, ${ }^{31}$ showed that this peptide adopted a different conformation at the MOP receptor. The conformations obtained from the initial "blind docking" were optimized by combined quantum mechanics/molecular mechanics computations using a flexible receptor environment. The pose characterized by the best binding energy showed $\mathrm{CONH}_{2}$ of Asp above the molecular plane in a pseudo-axial position and the pseudo-axial phenyl side chain of $\mathrm{Phe}^{4}$ below the molecular plane, while the phenyl of $\mathrm{Phe}^{3}$ and Tyr residues occupied positions nearly equatorial to the macrocycle ring (Fig. 3, 1 docking).

In order to find a rationale in the clear trend between the ring-size and MOP receptor affinity and selectivity, we analyzed the conformational behavior of the cyclopeptides in solution by MD simulation for $10 \mathrm{~ns}$ in a box of explicit water molecules. Due to the flexibility of the D-Lys connector, during the simulation of $\mathbf{1}$, the macrocycle adopted a variety of geometries. Reasonably, this observation accounts for the ability of the peptide to efficiently bind to the MOP receptor but with modest selectivity. On the other hand, due to the presence of a shorter D-Orn connector at position 2 of the sequence, the analysis of the trajectories of 2 revealed a lower conformational freedom and the occurrence of compact structures characterized by a $\beta$-turn centered on $\mathrm{Phe}^{3}-\mathrm{Phe}^{4}$ at the positions $i+1$ and $i+2$, stabilized by an $\mathrm{H}$-bond between $\mathrm{D}-\mathrm{LysC}=\mathrm{O}$ and AspNH (Fig. 3, 2). Possibly, the increased selectivity of 2 for the MOP can be correlated with the lower flexibility of the 16-membered ring. Interestingly, the $\beta$-turn geometry (Fig. 3, 2) nicely reproduces the disposition of the pharmacophoric side chains discussed above for $\mathbf{1}$ in its bioactive conformation.

A further reduction of the length of the connector was achieved by the introduction of D-Dab in 3. The analysis of the trajectories of the molecular dynamics simulations showed that this shorter connector behaves as a more rigid spacer, preventing the occurrence of the compact structures stabilized by $\mathrm{H}$-bonds as observed for 2 . A representative, almost planar geometry of 3 is shown in Fig. 3. This rigidity can explain the highly reduced MOP receptor affinity observed experimentally.

Finally, the conformational space accessible to the 14-membered cyclopeptides $\mathbf{4}$ and $\mathbf{5}$ was analyzed by MD. The cyclopeptide 4 containing $\mathrm{D}$-Dap revealed a frequent formation of the H-bonded $\beta$-turn secondary structure depicted in Fig. 3 which forces the pharmacophoric side chains to adopt the bioactive conformation proposed for $\mathbf{1}$. This behaviour is not completely unexpected. Indeed, 4 contains two $\beta$-amino acid residues, Asp and Dap, and it has been demonstrated that the presence of $\beta$-residues in cyclotetrapeptides and cyclopentapeptides tends to favor the formation of the well-defined $\gamma$ - or $\beta$-turn structures in opposite regions of the cyclic structure. ${ }^{32-34}$

As for cyclopeptide $\mathbf{5}$, which has the same sequence as $\mathbf{1}$ deprived of one Phe residue, the analysis of the trajectories of MD showed a strong tendency to give a $\beta$-turn centered on Phe-Asp, with an $\mathrm{H}$-bond between the $\mathrm{C}=\mathrm{O}$ of $\mathrm{D}$-Lys and
D-LysNHe (Fig. 2). Fig. 3 shows the remarkable similarity of 5 to the bioactive conformation of the prototypic MOP receptor agonist Jom-6. ${ }^{35}$ Due to the atypical sequence as compared to compounds 1-4, in particular to the different sequential position and a $3 \mathrm{D}$ display of the $\mathrm{CONH}_{2}$ side chain, 5 might bind to the MOP receptor taking advantage of other interactions.

\section{Conclusions}

A family of cyclic opioid peptides based on the structure of EM-2 with varying ring size was synthesized. The ring formation was achieved through an amide bond engaging the side chain amino functions of dibasic amino acids in position 2 and the $\beta$-carboxy group of Asp in position 5 . The ring size of the cyclic analogs as well as the solid support used for the synthesis determined the amount of dimeric side-products. In the binding studies, confirmed by a calcium mobilization functional test, the MOP selective or mixed MOP/KOP receptor ligands were identified depending on the size of the ring. The analysis of the biological results revealed a correlation between selectivity for the MOP receptor and the ring size. A reduction of the ring size increased MOP-selectivity. The MD calculations allowed us to rationalize this observation on the basis of conformations accessible for the cyclic structures. The obtained data highlighted the indirect role of changes in the size of the macrocycle on inducing the backbone conformation, which, in turn, oriented the side chains of the residues involved in the receptor interaction. Obtaining MOP receptor selective and non-selective analogs of EM-2 by introducing only small modifications into the peptide sequence shows the complexity of a binding phenomenon.

\section{Abbreviations}

Fmoc 9-Fluorenylmethyloxycarbonyl

Boc $\quad t$-Butyloxycarbonyl

TBTU 2-(1H-benzotriazol-1-yl)-1,1,3,3-tetramethyluronium tetrafluoroborate

TFA Trifluoroacetic acid

$t$-Bu tert-Butyl

Mtt Methyltrityl

O-2PhiPr Phenylisopropyl ester

2-Br-Z 2-Bromo-benzyloxycarbonyl

OFm Fluorenylmethyl ester

DCM Dichloromethane

DMF Dimethylformamide

TIS Triisopropylsilane

\section{Acknowledgements}

This work was supported by a grant from the Medical University of Lodz, no. 503/1-156-02/503-01, and a grant from the Medical University of Lodz for young researchers, no. 502-03/ 1-156-02/502-14-139 (JP). 


\section{References}

1 G. A. Olson, R. D. Olson, A. L. Vaccarino and A. J. Kastin, Peptides, 1998, 19, 1791-1843.

2 J. E. Zadina, L. Hackler, L. J. Ge and A. J. Kastin, Nature, 1997, 386, 499-502.

3 R. Przewlocki, D. Labuz, J. Mika, B. Przewlocka, C. Tomboly and G. Toth, Ann. N. Y. Acad. Sci., 1999, 897, 154-164.

4 A. M. Wilson, R. D. Soignier, J. E. Zadina, A. J. Kastin, W. L. Nores, R. D. Olson and G. A. Olson, Peptides, 2000, 21, 1871-1874.

5 J. Fichna, A. Janecka, J. Costentin and J. C. do-Rego, Pharmacol. Rev., 2007, 59, 88-123.

6 S. Van Dorpe, A. Adriaens, I. Polis, K. Peremans, J. Van Bocxlaer and B. De Spiegeleer, Peptides, 2010, 31, 1390-1399.

7 L. Gentilucci, R. De Marco and L. Cerisoli, Curr. Pharm. Des., 2010, 16, 3185-3203.

8 W. X. Liu and R. Wang, Med. Res. Rev., 2012, 32, 536-580.

9 A. Janecka, R. Staniszewska and J. Fichna, Curr. Med. Chem., 2007, 14, 3201-3208.

10 J. Piekielna, R. Perlikowska, K. Gach and A. Janecka, Curr. Drug Targets, 2013, 14, 798-816.

11 G. Cardillo, L. Gentilucci, A. Tolomelli, R. Spinosa, M. Calienni, A. R. Qasem and S. Spampinato, J. Med. Chem., 2004, 47, 5198-5203.

12 A. Bedini, M. Baiula, L. Gentilucci, A. Tolomelli, R. De Marco and S. Spampinato, Peptides, 2010, 31, 2135-2140.

13 A. Mollica, F. Pinnen, A. Stefanucci, F. Feliciani, C. Campestre, L. Mannina, A. P. Sobolev, G. Lucente, P. Davis, J. Lai, S. W. Ma, F. Porreca and V. J. Hruby, J. Med. Chem., 2012, 55, 3027-3035.

14 A. Mollica, F. Pinnen, A. Stefanucci, L. Mannina, A. P. Sobolev, G. Lucente, P. Davis, J. Lai, S. W. Ma, F. Porreca and V. J. Hruby, J. Med. Chem., 2012, 55, 8477-8482.

15 R. Perlikowska, J. C. do-Rego, A. Cravezic, J. Fichna, A. Wyrebska, G. Toth and A. Janecka A, Peptides, 2010, 31, 339-345.

16 J. Fichna, R. Perlikowska, A. Wyrębska, K. Gach, J. Piekielna, J. C. do-Rego, G. Toth, A. Kluczyk, T. Janecki and A. Janecka, Bioorg. Med. Chem., 2011, 19, 6977-6981.

17 J. Piekielna, A. Kluczyk, R. Perlikowska and A. Janecka, Peptides, 2014, 55, 32-40.

18 R. Perlikowska, D. Malfacini, M. C. Cerlesi, G. Calo', J. Piekielna, L. Floriot, T. Henry, J. C. do-Rego, C. Tömböly, A. Kluczyk and A. Janecka, Peptides, 2014, 55, 145-150.
19 A. Misicka, A. W. Lipkowski, R. Horvath, P. Davis, T. H. Kramer, H. I. Yamamura and V. J. Hruby, Life Sci., 1992, 51, 1025-1032.

20 B. R. Conklin, Z. Farfel, K. D. Lustig, D. Julius and H. R. Bourne, Nature, 1993, 363, 274-276.

21 E. Kostenis, L. Martini, J. Ellis, M. Waldhoer, A. Heydorn, M. M. Rosenkilde, P. K. Norregaard, R. Jorgensen, J. L. Whistler and G. Milligan, J. Pharmacol. Exp. Ther., 2005, 313, 78-87.

22 V. Camarda and G. Calo', Methods Mol. Biol., 2013, 937, 293-306.

23 HyperChem Release 8.0.3, Hypercube Inc., 1115 NW 4th St. Gainesville, FL 32608, USA, 2007.

24 W. D. Cornell, P. Cieplak, C. I. Bayly, I. R. Gould, K. M. Merz, D. M. Ferguson, D. C. Spellmeyer, T. Fox, J. W. Caldwell and P. A. Kollman, J. Am. Chem. Soc., 1995, 117, 5179-5197.

25 W. L. Jorgensen, J. Chandrasekhar, J. Madura, R. W. Impey and M. L. Klein, J. Chem. Phys., 1983, 79, 926-935.

26 H. J. C. Berendsen, J. P. M. Postma, W. F. van Gunsteren, A. Di Nola and J. R. Haak, J. Chem. Phys., 1984, 81, 36843690 .

27 C. Yue, J. Thierry and P. Potier, Tetrahedron Lett., 1993, 34, 323-326.

28 A. Aletras, K. Barlos, D. Gatos, S. Koutsogianni and P. Mamos, Int. J. Pept. Protein Res., 1995, 45, 488-496.

29 J. Piekielna, L. Gentilucci, R. De Marco, R. Perlikowska, A. Adamska, J. Olczak, M. Mazur, R. Artali, J. Modranka, T. Janecki, C. Tömböly and A. Janecka, Bioorg. Med. Chem., 2014, 22, 6545-6551.

30 L. Gentilucci, F. Squassabia, R. De Marco, R. Artali, G. Cardillo, A. Tolomelli, S. Spampinato and A. Bedini, FEBS J., 2008, 275, 2315-2337.

31 A. Manglik, A. C. Kruse, T. S. Kobilka, F. S. Thian, J. M. Mathiesen, R. K. Sunahara, L. Pardo, W. I. Weis, B. K. Kobilka and S. Granier, Nature, 2012, 485, 321326.

32 F. Schumann, A. Müller, M. Koksch, G. Müller and N. Sewald, J. Am. Chem. Soc., 2000, 122, 12009-12010.

33 M. P. Glenn, M. J. Kelso, J. D. A. Tyndall and D. P. Fairlie, J. Am. Chem. Soc., 2003, 125, 640-641.

34 A. S. Norgren, F. Büttner, S. Prabpai, P. Kongsaeree and P. I. Arvidsson, J. Org. Chem., 2006, 71, 6814-6821.

35 C. B. Fowler, I. D. Pogozheva, A. L. Lomize, H. LeVine 3rd and H. I. Mosberg, Biochemistry, 2004, 43, 15796-15810. 